\title{
Horses Experimentally Infected with Sarcocystis neurona Develop Altered Immune Responses In Vitro
}

Author(s): Sharon G. Witonsky, Siobhan Ellison, Jibing Yang, Robert M. Gogal, Heather Lawler, Yasuhiro Suzuki , Namalwar Sriranganathan, Frank Andrews, Daniel Ward, and David S. Lindsay Source: Journal of Parasitology, 94(5):1047-1054. 2008.

Published By: American Society of Parasitologists

DOI: http://dx.doi.org/10.1645/GE-1441.1

URL: http://www.bioone.org/doi/full/10.1645/GE-1441.1

BioOne (www.bioone.org) is a nonprofit, online aggregation of core research in the biological, ecological, and environmental sciences. BioOne provides a sustainable online platform for over 170 journals and books published by nonprofit societies, associations, museums, institutions, and presses.

Your use of this PDF, the BioOne Web site, and all posted and associated content indicates your acceptance of BioOne's Terms of Use, available at www.bioone.org/page/terms of use.

Usage of BioOne content is strictly limited to personal, educational, and non-commercial use. Commercial inquiries or rights and permissions requests should be directed to the individual publisher as copyright holder. 


\title{
HORSES EXPERIMENTALLY INFECTED WITH SARCOCYSTIS NEURONA DEVELOP ALTERED IMMUNE RESPONSES IN VITRO
}

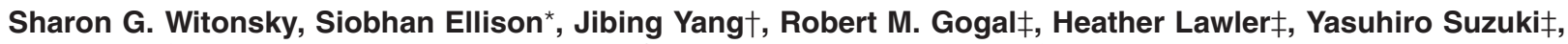 \\ Namalwar Sriranganathan $\ddagger$, Frank Andrews $\S$, Daniel Ward\|, and David S. Lindsay $\ddagger$ \\ Department of Large Animal Clinical Sciences, Phase II, Duck Pond Dr., Virginia-Maryland Regional College of Veterinary Medicine, \\ Virginia Tech, Blacksburg, Virginia 24061-0442.e-mail: switonsk@vt.edu
}

\begin{abstract}
Equine protozoal myeloencephalitis (EPM) due to Sarcocystis neurona infection is 1 of the most common neurologic diseases in horses in the United States. The mechanisms by which most horses resist disease, as well as the possible mechanisms by which the immune system may be suppressed in horses that develop EPM, are not known. Therefore, the objectives of this study were to determine whether horses experimentally infected with $S$. neurona developed suppressed immune responses. Thirteen horses that were negative for $S$. neurona antibodies in serum and cerebrospinal fluid (CSF) were randomly assigned to control $(\mathrm{n}=5)$ or infected $(\mathrm{n}=8)$ treatment groups. Neurologic exams and cerebrospinal fluid analyses were performed prior to, and following, $S$. neurona infection. Prior to, and at multiple time points following infection, immune parameters were determined. All 8 S. neurona-infected horses developed clinical signs consistent with EPM, and had S. neurona antibodies in the serum and CSF. Both infected and control horses had increased percentages $(P<0.05)$ of B cells at 28 days postinfection. Infected horses had significantly decreased $(P<0.05)$ proliferation responses as measured by thymidine incorporation to nonspecific mitogens phorbol myristate acetate (PMA) and ionomycin (I) as soon as 2 days postinfection.
\end{abstract}

Sarcocystis neurona is the predominant causative agent of equine protozoal myeloencephalitis (EPM) in horses in the United States (Dubey et al., 1991). Horses are exposed through the ingestion of sporocysts in contaminated feedstuffs (MacKay et al., 1997a, 1997b). Following exposure, most horses become seropositive, but do not display clinical signs during their lifetime. However, in a small $(0.5-1 \%)$ percentage of horses, $S$. neurona migrates to the central nervous system to cause encephalitis (MacKay et al., 1997b; National Animal Health Monitoring System [NAHMS], 2001). Currently, there is a critical gap of knowledge regarding the mechanisms by which $S$. neurona traverses the body, penetrates the blood-brain barrier, and causes disease. Furthermore, there have also been questions raised about the immunocompetence of the horses that develop disease. As only a small percentage of infected horses develop clinical signs, it appears that there may be other factors, such as immune competence or genetics, that could contribute to the development of EPM.

Regarding immune function, it is not clear whether horses have a suppressed immune function prior to infection, thus increasing the likelihood that they develop disease, or whether horses become infected and then their immune system is suppressed either because of $S$. neurona-specific or nonspecific factors (Saville et al., 2000; Tornquist et al., 2001; Spencer et al., 2004, 2005). With other protozoan agents, e.g., Toxoplasma gondii, it has been shown that the protozoans are capable of suppressing the host immune response (Gazzinelli et al., 1993;

Received 24 August 2007; revised 28 November 2007, 22 January 2008; accepted 23 January 2008.

* Pathogenes Inc., Molecular Biology, 15471 NW 112th Avenue, P.O. Box 970, Fairfield, Florida 32634

$\dagger$ Department of Immunology, College of Veterinary Medicine, 4700 Hillsborough Street, North Carolina State University, Raleigh, North Carolina 27606.

$\ddagger$ Department of Biomedical Sciences and Pathobiology, VirginiaMaryland Regional College of Veterinary Medicine, Virginia Tech, 1410 Prices Fork Road, Blacksburg, Virginia 24061-0442.

$\S$ Department of Large Animal Clinical Sciences, College of Veterinary Medicine, 2407 River Drive, University of Tennessee, Knoxville, Tennessee 37996.

|| Rutgers Department of Agricultural Research and Extension Center, 121 Northville Road, Rutgers, Bridgeton, New Jersey 08302.
Shapira et al., 2004). Therefore, it seems plausible that $S$. neurona could also suppress the host immune response, although this has not been evaluated. With regard to the possibility that horses are immunocompromised prior to infection, Saville et al. (2000) demonstrated that horses that are competing, pregnant, in training, traveling, or have a few other risk factors, have an increased risk of developing disease. This study implies that these stressful lifestyles may cause at least transient immune dysfunction that may increase the susceptibility of the horse to $S$. neurona-mediated encephalitis.

More recently, there have been a few studies examining both experimentally infected and naturally infected horses. These studies suggest that EPM-affected horses may have an altered or compromised immune response compared to horses that do not have EPM. Tornquist et al. (2001) and Spencer et al. (2004, 2005) both demonstrated that EPM-affected horses have suppressed immune responses to antigen-specific mitogens. Furthermore, Spencer et al. (2005) established that lymphocytes from horses with EPM had increased interleukin-4 (IL-4) expression compared to normal horses. Interleukin-4 is associated with a CD4 T-helper type 2 (Th2) response, which is not favorable to clearance of many intracellular agents, e.g., T. gondii, Brucella spp. (Gazzinelli et al., 1992, 1993; Splitter et al., 1996; Suzuki 2002a, 2002b). Rather than mounting a Th2 response, ideal protection against some intracellular pathogens, including $S$. neurona, consists of a strong cell-mediated immune response. Optimally, this includes both CD4 Th1 and CD8 cells, which produce interferon-gamma (IFN-gamma), based on murine studies (Dubey and Lindsay, 1998; Witonsky et al., 2003a, 2003b; Witonsky et al., 2005).

Because there have been many challenges in investigating $S$. neurona and EPM when naturally occurring cases have been utilized, researchers have employed both murine and equine models. From the murine models, it has been determined that IFN-gamma mediated activity is critical for a protective immune response to prevention and/or minimizing clinical disease (Dubey and Lindsay, 1998; Witonsky et al., 2003a, 2003b). Furthermore, Witonsky et al. (2005) demonstrated that CD8 cells were critical to protection in a C57BL/6 murine model. Based on these data, we hypothesized that functional cytotoxic $\mathrm{T}$ cells subset 1 (CD8 Tc1) as well as CD4 Th1 cells and other IFN- 
gamma-producing cells (Sellon et al., 2004) are optimal for prevention of encephalitis associated with $S$. neurona infection. Therefore, it appears plausible that horses that develop EPM may have altered immune function of any of these IFN-gamma-producing cell populations either prior to or as a result of the $S$. neurona infection.

To determine whether horses that are infected with $S$. neurona develop altered immune function, specifically of CD4 or CD8 cells, we experimentally infected horses with $S$. neurona. Our hypothesis was that horses experimentally infected with $S$. neurona would develop clinical neurologic signs, and they would have suppressed CD8 responses in vitro compared to uninfected controls. To assess the immune response, we determined whether there were changes in immune cell subsets as measured by flow cytometry. We evaluated immune function based on antigen-specific and nonspecific proliferation and IFN-gamma production.

\section{MATERIALS AND METHODS}

\section{Animals}

Thirteen horses were employed for this study. There were 11 yearlings, 1 12-yr-old, and 1 19-yr-old horse. There were 11 quarter horses or quarter-horse crosses, 1 Arabian, and 1 American paint horse. Of these, there were 4 females, 3 geldings, and 6 stallions. All of the horses were negative for cervical disease, as determined by cervical radiography. All horses were vaccinated with eastern and western encephalitis, rhinopneumonitis, influenza virus, and West Nile virus. They were dewormed with ivermectin and had negative Coggins tests prior to the study; all horses were seronegative for equine viral arteritis (EVA). Complete neurologic exams and cerebral spinal fluid (CSF) taps were performed, and all horses were negative for $S$. neurona antibodies in the CSF based on both Western blot (WB) analysis (Granstrom et al., 1993) and surface antigen-1 [SAG-1]) analysis (Ellison et al., 2003a). Western blot analysis was performed at commercial laboratories (EBI/ IDEXX, Lexington, Kentucky, and Neogen, Lexington, Kentucky). SAG-1 ELISAs were performed by Ellison (Pathogenes, Inc., Fairfield, Florida). All horses were seronegative for $S$. neurona antibodies based on SAG-1 ELISA, and there were 2 low positive by WB. Horses were randomly divided into controls $(n=5)$ and infected $(n=8)$.

\section{Experimental infection}

For infection studies, horses were infected with S. neurona (SN3) merozoites as previously described (Ellison et al., 2003b, 2004). Briefly, peripheral blood was collected from each horse in EDTA tubes. Peripheral blood mononuclear cells were isolated from the blood utilizing Optiprep (Sigma, St. Louis, Missouri). For the horses in the infected group, enriched cells from each horse were then infected with 6,000 $S$. neurona merozoites in media. Infected cells were cultured overnight at $37 \mathrm{C}$ in $5 \% \mathrm{CO}_{2}$. The following day, each horse was given back autologous cells with or without $S$. neurona intravenously. Horses were infected once daily for 14 days (Ellison et al., 2003b, 2004).

\section{Experimental design}

Baseline blood samples for immune function were collected 13 days (Day-13) prior to infection. Horses were infected as described above (Ellison et al., 2004). Horses were maintained in Florida on open pasture with free exercise. Beginning at Day 14 postinfection (PI), all horses were lounged daily for $5 \mathrm{~min}$ each direction. Blood was collected to assess alterations in immune function at Days 1, 2, 5, 13, 28, and 48 PI. Repeat neurologic exams, serologic analysis, and CSF taps were performed at Days 28 and 55 PI.

\section{Clinical pathology}

Complete blood counts with differentials and chemistry panels were performed on all of the horses at days 1, 7, 41, 46, and 65 PI (Professional Veterinary Laboratory, Ocala, Florida).

\section{Collection of blood samples for immune function studies}

From each horse, approximately $30-40 \mathrm{ml}$ of peripheral venous blood was obtained in tubes containing lithium heparin anticoagulant (Vacutainer tubes, Fisher Scientific, Suwanee, Georgia) by aseptic venipuncture from either left or right jugular vein from all horses. Two horses from the Virginia Maryland Regional College of Veterinary Medicine teaching herd were used as internal controls. Control blood, to simulate storage of shipped samples, was stored overnight at $4 \mathrm{C}$ in the refrigerator. Blood was collected from the horses in Florida and shipped at $4 \mathrm{C}$ via overnight carrier.

All samples were analyzed on the following day. All stored or shipped blood was warmed up to room temperature $(23 \pm 2 \mathrm{C})$ before evaluation.

\section{Isolation of peripheral blood mononuclear cells (PBMCs)}

PBMCs were isolated from whole blood by density gradient centrifugation, as previously described (Witonsky et al., 2003c; Yang et al., 2006). Briefly, whole blood at room temperature was diluted with phosphate-buffered saline (PBS, Mediatech, Herndon, Virginia) at a ratio of 1:2 before the diluted blood was carefully layered on Lymphoprep (Lymphoprep 1.077, Greine, New Jersey). All reagents were at room temperature to optimize for enriched lymphocytes. Samples were centrifuged at $1,500 \mathrm{rpm}(350 \mathrm{~g})$ for $30 \mathrm{~min}$ at $23 \mathrm{C}$. The buffy coat containing the enriched leukocytes was collected and diluted minimally with an equal volume of PBS. Cells were centrifuged at 1,300 rpm (250 $g$ ) for $10 \mathrm{~min}$ at $4 \mathrm{C}$. The supernatant was removed from each tube and each sample was resuspended in PBS, washed twice, and centrifuged at $1,300 \mathrm{rpm}(250 \mathrm{~g})$ for $5 \mathrm{~min}$ at $4 \mathrm{C}$. Cell counts were determined with the CASY-1 (TTC cell counter and analyzer system, Sharfe System, GMbH, Reutingen, Germany). Cells were resuspended to a final concentration of $2 \times 10^{6} / \mathrm{ml}$ in complete RPMI 1640 (Cellgro RPMI $16401 \times$; Thomas Scientific) with 1\% L-glutamine, HEPES buffer 25 $\mathrm{mM}, 10 \%$ heat-inactivated fetal bovine serum (Atlanta Biologicals, Lawrenceville, Georgia), penicillin (50 IU/ml), and streptomycin $(50$ $\mathrm{IU} / \mathrm{ml}$ ) (Sigma). The PBMC were then used in the following assays.

\section{Cytospin preparation}

PBMC $\left(0.25 \times 10^{6}\right.$ cells $)$ were diluted with $100 \mu$ PBS and loaded in a centrifugation chamber containing a glass slide. Each chamber was placed into a cytocentrifuge (Cyto-Teck centrifuge, Sakura Finetechnical Co., Tokyo, Japan), and centrifuged at $500 \mathrm{rpm}(30 \mathrm{~g})$ for $5 \mathrm{~min}$. The slides were air dried, followed by fixing and staining with modified Wright stain. Coverslips were placed, and 5-point differentials were performed on 100 cells per sample (Witonsky et al., 2003c).

\section{Flow cytometry}

Single staining was performed on each sample. For each sample, 5 $\times 10^{5}$ cells per stain were placed in a 96-well round bottom plate (Corning Glass Works, Corning, New York). Cells were washed with PBS (4 C) and centrifuged at 1,300 rpm $(250 \mathrm{~g})$ for $5 \mathrm{~min}$ at $4 \mathrm{C}$. The following primary monoclonal antibodies were added to the appropriate individually aliquoted sample: mouse anti-equine CD4 (cell line $\mathrm{HB} 61 \mathrm{~A}, \mathrm{IgG}_{1}$, VMRD, Pullman, Washington), mouse anti-equine CD8 (cell line HT14A, $\mathrm{IgG}_{1}$; VMRD), B-cell (mouse anti-equine CD5 antibody, cell line $\mathrm{B} 29 \mathrm{~A}, \mathrm{IgG}_{2 \mathrm{a}} ; \mathrm{VMRD}$ ), and $\mathrm{DH} 59 \mathrm{~b}$ antibody (mouse anti-equine $\mathrm{IgG}_{1}$; VMRD), which stains equine neutrophils and monocytes. The latter 2 populations can be differentiated based on granularity of the cells. Cells were incubated with $0.5 \mu \mathrm{g}$ of the primary antibody for 20 $\mathrm{min}$ at $4 \mathrm{C}$. Cells were washed, and then incubated for $20 \mathrm{~min}$ at $4 \mathrm{C}$ with $0.5 \mu \mathrm{g}$ secondary antibody of either fluorescein isothiocyanate (FITC) rat anti-mouse $\mathrm{IgG}_{1}$ (for conjugation to CD4, CD8, and DH59b antibodies) (Pharmingen, San Diego, California) or phycoerythrin (PE) rat anti-mouse $\operatorname{IgG}_{2 \mathrm{a}}$ (for conjugation to the B-cell antibody) (Pharmingen). Unstained samples were incubated with PBS. Cells were washed and resuspended in $100 \mu \mathrm{l}$ PBS (4 C) for flow cytometry (EPICS XL flow cytometer, Coulter, Hialeah, Florida). One hundred microliters of 7-AAD (7-amino actinomycin D) at $0.1 \mu \mathrm{g} / \mathrm{ml}$ (Molecular Probes, Eugene, Oregon) was added to each sample. The plate was incubated for no more than $30 \mathrm{~min}$ on ice in the dark. Five or 10,000 cells per gated sample were collected by the flow cytometer. Based on the intensity of staining, cells were classified by their subset and as either 7AAD dull 
(live cells), 7AAD ${ }^{\text {moderate }}$ (early apoptosis), or 7AAD ${ }^{\text {bright }}$ (late apoptosis) (Gogal et al., 2000; Yang et al., 2006).

\section{Live merozoite preparation}

Sarcocystis neurona merozoites (SN-37R) were grown and maintained in African green monkey (Cercopithecus aethiops) kidney cells (CV-1 cells, ATTC CCL-70, American Type Culture Collection, Rockville, Maryland). Merozoites were harvested from CV-1 cells by removing the media (RPMI with L-glutamine, HEPES buffer $25 \mathrm{mM}, 2 \%$ FBS, $5 \mathrm{ml}$ of sodium pyruvate solution $/ 500 \mathrm{ml}$ bottle, $50 \mathrm{IU} / \mathrm{ml}$ of penicillin/streptomycin solution). The merozoite suspension was filtered through a $3-\mu \mathrm{M}$ filter and centrifuged at $1,500 \mathrm{rpm}(350 \mathrm{~g})$ for $10 \mathrm{~min}$ at room temperature, and then resuspended in complete media. The merozoites were enumerated with a hematocytometer and resuspended at a concentration of $1 \times 10^{5} / \mathrm{ml}$ with complete media (Lindsay et al., 2000).

\section{Lymphocyte proliferation assays}

A $100-\mu 1$ aliquot of equine enriched lymphocytes $\left(2 \times 10^{6} / \mathrm{ml}\right)$ was cultured in triplicate wells together with $100 \mu \mathrm{l}$ of the appropriate optimized mitogen or live merozoites $\left(1 \times 10^{5} / \mathrm{ml}\right)$. Mitogens included 2 $\mu \mathrm{g} / \mathrm{ml}$ or $10 \mu \mathrm{g} / \mathrm{ml}$ concanavalin (ConA, Sigma), $2 \mu \mathrm{g} / \mathrm{ml}$ pokeweed mitogen (PWM; Sigma), $40 \mathrm{ng} / \mathrm{ml}$ phorbol myristate acetate (PMA) and $20 \mathrm{pg} / \mathrm{ml}$ ionomycin (Sigma). Final concentrations of the mitogens in cell suspension were PWM: $1 \mu \mathrm{g} / \mathrm{ml}$, ConA: 1 and $5 \mu \mathrm{g} / \mathrm{ml}$, PMA 20 $\mathrm{ng} / \mathrm{ml}$, and ionomycin $10 \mathrm{pg} / \mathrm{ml}$. Cells were incubated at $37 \mathrm{C}$ in humidified $5 \% \mathrm{CO}_{2}$ and pulsed with $1 \mu \mathrm{Ci}{ }^{3} \mathrm{H}$-thymidine (MP Biomedicals, Irvine, California) after $48 \mathrm{hr}$ culture. Plates were harvested 18$24 \mathrm{hr}$ later with the use of a Filtermake harvester (Packard Bioscience, Billerica, Massachusetts). Delta counts per minute ( $\Delta \mathrm{CPM})$ was calculated as the mean CPM of cells with mitogens minus mean CPM of cells without mitogens (Witonsky et al., 2003c; Yang et al., 2006).

\section{SAG-1 blastogenesis assay}

Recombinant SAG-1 (Spencer et al., 2004) $(50 \mu \mathrm{l})$ of $10 \mu \mathrm{g} / \mathrm{ml}$ was added to 96 round-bottom wells overnight at $4 \mathrm{C}$. The plate was then washed twice with PBS prior to adding cells.

A $100-\mu l$ aliquot of enriched equine lymphocytes $\left(2 \times 10^{6} / \mathrm{ml}\right)$ was cultured in triplicate. Media or ConA $(5 \mu \mathrm{g} / \mathrm{ml})(100 \mu \mathrm{l} /$ well $)$ was added to noncoated wells. Samples were run in triplicate. Cells were incubated at $37 \mathrm{C}$ in humidified $5 \% \mathrm{CO}_{2}$ incubator and pulsed with $1 \mu \mathrm{Ci}{ }^{3} \mathrm{H}-$ thymidine (MP Biomedicals) after $72 \mathrm{hr}$ culture. Plates were harvested 18-24 hr later with the use of a Filtermake harvester (Packard Bioscience). Delta counts per minute $(\triangle \mathrm{CPM})$ was calculated as the mean CPM of cells with mitogens minus mean CPM of cells from unstimulated cells in media (Witonsky et al., 2003; Yang et al., 2006).

\section{Interferon-gamma cytokine production}

Cells were plated in a 96-well round-bottom plate at $5 \times 10^{5}$ cells per well. A 100- $\mu$ l aliquot of the appropriate mitogen (ConA $10 \mu \mathrm{g}$ / $\mathrm{ml})$ or merozoites $\left(10^{4} /\right.$ well $)$ or media only was added with brefeldin $(5 \mu \mathrm{g} / \mathrm{ml})$ (Epicentre, Madison, Wisconsin). Brefeldin is a protein transport inhibitor that is added during the incubation period to prevent secretion of cytokines. Thus, the cytokines can then be detected by flow cytometry at the culmination of the incubation period. Cells were stimulated overnight at $37 \mathrm{C}$ in humidified $5 \% \mathrm{CO}_{2}$ incubator. Cells were stained for CD4 or CD8 followed by IFN $-\gamma$ with the use of a modified protocol (Belz et al., 2001; Hines et al., 2003). Briefly, plates were centrifuged at $1,300 \mathrm{rpm}(250 \mathrm{~g}) \times 5 \mathrm{~min}$. Supernatants were discarded. Cell surface staining for CD4 or CD8 was performed as described above except that brefeldin $(1 \mu \mathrm{g} / \mathrm{ml})$ was added to all solutions. Cells were then washed with PBS. Cells were then fixed in $2 \%$ paraformaldehyde for $15 \mathrm{~min}$ at $4 \mathrm{C}$. Cells were washed and permeabilized with $0.5 \%$ saponin for $10 \mathrm{~min}$ at room temperature. Cells were then washed in permeabilization (saponin) buffer and then bovine IFN- $\gamma$ (mouse antibovine IgG1; Serotec, Raleigh, North Carolina) that had already been complexed with Zenon PE-IgG1 beads (Molecular Probes, Carlsbad, California) was added to the cells for $30 \mathrm{~min}$ at $4 \mathrm{C}$. Following incubation, cells were washed and 5,000 gated events per sample were analyzed by the Coulter flow cytometer.

\section{Statistical analysis}

Analysis of variance (ANOVA) was conducted with the use of the MIXED procedure of the SAS system (version 8.9.1.2, SAS Institute Inc., Cary, North Carolina) to test for main effects of infection status and day as well as their interaction. Standard residual plots were used to assess model adequacy. Results are expressed as mean \pm SEM. Significance was $P<0.05$.

\section{RESULTS}

\section{Clinical signs}

Three of $8 \mathrm{~S}$. neurona-infected horses developed clinical neurologic signs consistent with EPM by Day 6 PI, and the remaining 5 of 8 infected horses developed clinical neurologic signs by Day 15 PI. Sarcocystis neurona-infected horses developed a minimum of Grade II ataxia (Reed, 1998) during the course of the study. All S. neurona-infected horses were seropositive by Day 55 PI based on WB as well as SAG-1 ELISA. All $S$. neurona-infected horses were positive for $S$. neuronspecific antibodies in the CSF by SAG-1 ELISA by Day 55 PI. Seven of 8 horses were positive by WB for antibodies to $S$. neurona in the CSF at Day 55 PI. Only 2 CSF taps were performed, the last of which was at Day 55 PI. The eighth horse was not positive for antibodies to $S$. neurona in the CSF at this time as detected by WB, but did have antibodies in the CSF based on SAG-1 ELISA. The horse had neurologic signs consistent with EPM, and the horse's serum titer was 1:360. Ellison has previously demonstrated differences in S. neurona antibody detection based on the test and conditions employed (Ellison et al., 2002).

\section{Clinical pathology}

Abnormal results of complete blood counts and leukocyte differentials on the horses at the various time points are summarized as follows. Prior to infection, 9 of 13 horses had low hematocrit values (Hct) between 26 and $31 \%$ (reference interval $34-50 \%$ ), but all 13/13 horses had red-blood-cell (RBC) counts within the normal reference interval. One horse was neutropenic $(1,080$ cells/ $\mu \mathrm{l}$; reference interval $2,450-6,500$ cells/ $\mu 1)$. One horse had an increased total protein (hyperproteinemia) (8 $\mathrm{g} / \mathrm{dl}$, reference range $5.1-7.2 \mathrm{~g} / \mathrm{dl}$ ) and 3 of 13 horses had slightly increased fibrinogen levels (hyperfibrinogenemia) (each with $500 \mathrm{mg} / \mathrm{dl}$, reference interval 100-400 mg/dl). At Day $1 \mathrm{PI}, 8$ of 13 horses were anemic based on low RBC counts. Of these, 6 of 8 were from the infected treatment group and 2 of 8 were from the uninfected treatment group. By Day 7 PI, 2 of 13 horses had mildly low RBC counts, but these were from the control group, and they did not previously have low RBC counts. At each subsequent time point, there was 1 horse with a low RBC count, but the affected horse was inconsistent between days.

Results of the chemistry panels showed no significant differences between infected and control horses. One of the 13 horses that was from the infected treatment group had an increased GGT 80 IU/L (reference interval 5-29 IU/L) on Day 7 and Day $1 \mathrm{PI}$, but the value was within the normal range after Day 1 PI. Other mild abnormalities were found, but these were not considered important or related to $S$. neurona infection. 


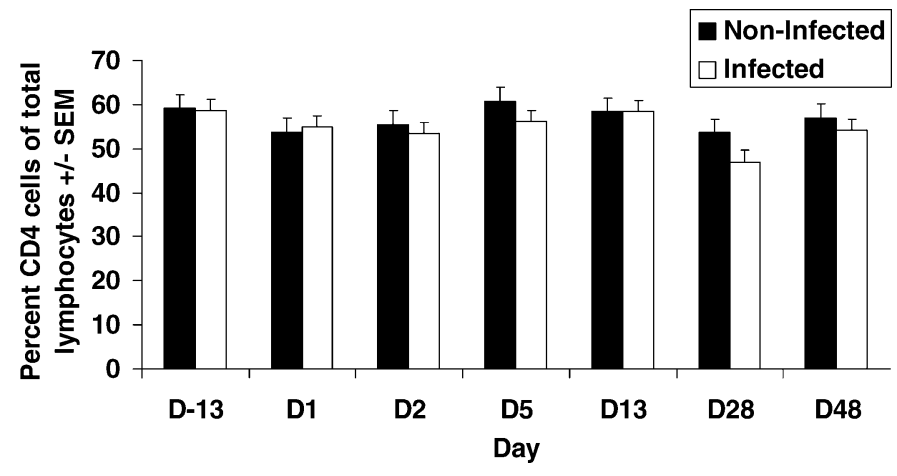

FIGURE 1. Percentage of CD4 T cells of total lymphocytes. Results were expressed as mean percentage \pm SEM. $n=8$ infected and $n=5$ control horses. Day is day prior to (D-13) or following infection, e.g., D1.

\section{Leukocyte expression and viability}

Leukocyte subset expression was not altered by $S$. neurona infection compared to controls early postinfection (Figs. 1-3). However, on Day $28 \mathrm{PI}$, there was a transient significant increase $(P<0.05)$ in the percentage of neutrophils $(11.2 \%$ control vs. $17 \%$ infected). Also on Day 28 PI, there was a significant increase $(P<0.05)$ in $\mathrm{B}$-cell percentages in both the infected and control horses compared to baseline, but no significant differences $(P>0.05)$ between infected versus control horses (Fig. 3).

There were some significant $(P<0.05)$ changes in viability as determined by 7-AAD staining of immune cell subsets. On Day 28 PI, there was a decrease in the percent viable CD8 cells (89.99\% viable of controls vs. $76.92 \%$ viable in infected population). Additionally, by Day 48 PI, there was a significant decrease $(P<0.05)$ in the percentage of viable B cells in the infected $(45.57 \%)$ horses compared to the control $(63.04 \%)$ horses. No other significant differences in viability were detected.

\section{Cytology}

Cytospins were prepared and analyzed primarily as a means of confirming the purity of lymphocytes from our enrichment method. We have previously determined that if there is a moderate amount of neutrophil contamination, i.e., $10 \%$, this can affect our proliferation responses (Witonsky et al., 2003c). Neu-

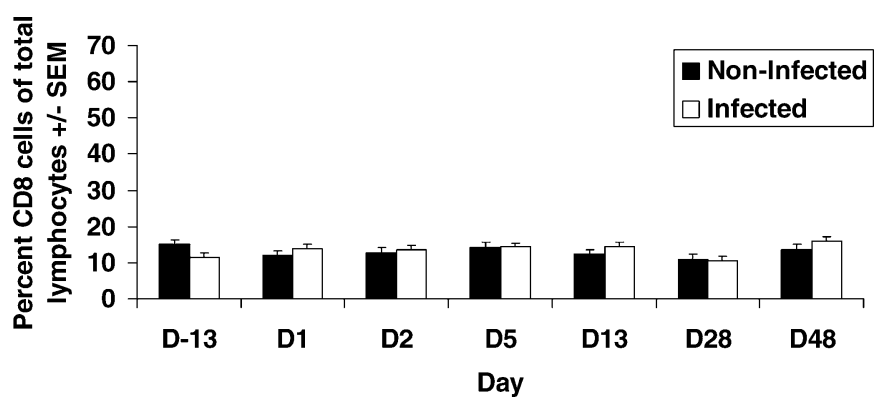

Figure 2. Percentage of CD8 T cells of total lymphocytes. Results were expressed as mean percentage \pm SEM. $\mathrm{n}=8$ infected and $\mathrm{n}=5$ control horses. Day is day prior to (D-13) or following infection, e.g., D1.

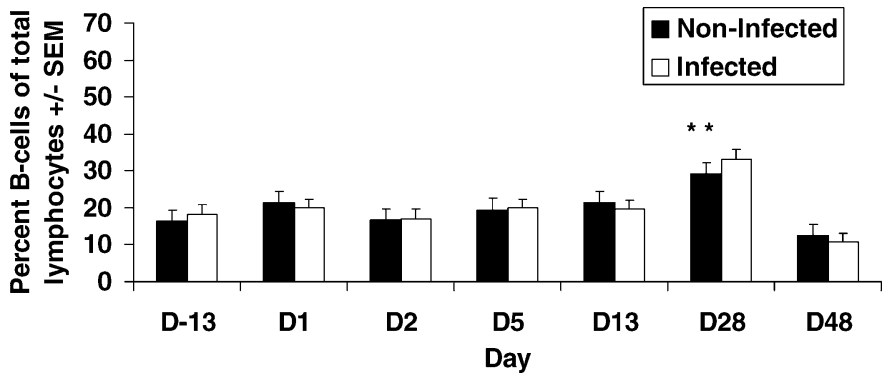

FIGURE 3. Percentage of B cells of total lymphocytes. Results were expressed as mean percentage \pm SEM. $n=8$ infected and $n=5$ control horses. Asterisk indicates a significant difference between B cells in horses, both infected and control, at Day 28 compared to baseline (D13). Day is day prior to (D-13) or following infection, e.g., D1.

trophil contamination has been shown to cause decreased proliferation responses (Witonsky et al., 2003c). A very limited number of samples had neutrophil contamination. This was a covariate in the statistical analysis.

\section{Leukocyte proliferation assays}

There were no significant differences in proliferation responses to ConA and PWM between infected and control horses. However, lymphocyte proliferation in response to PMA/I was significantly lower $(P<0.05)$ in infected horses compared to control horses at Days 2 and 28 PI (Fig. 4).

There were no significant differences in lymphocyte proliferation following $S$. neurona-antigen-specific (merozoites) stimulation between control and $S$. neurona-infected horses (Fig. 5). Additionally, there were no significant differences $(P$ $>0.05)$ in response to SAG-1 antigen between $S$. neuronainfected versus control horses (data not shown).

\section{Leukocyte-stimulated interferon-gamma production}

Cellular immune function was also assessed based on IFNgamma cytokine production. Cells were stimulated overnight with either media only, ConA $(10 \mu \mathrm{g} / \mathrm{ml})$ or $S$. neurona merozoites $\left(10^{4} /\right.$ well). There were no significant differences in IFN-gamma production by CD4 cells of $S$. neurona-infected

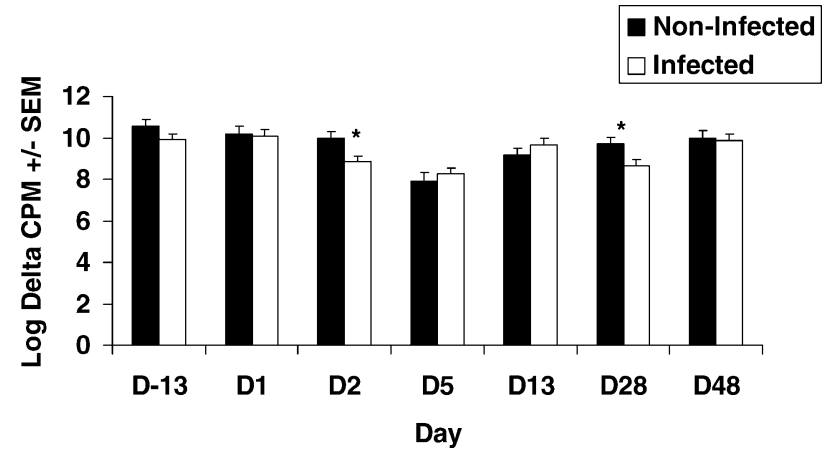

FIGURE 4. Effect of experimental infection with Sarcocystis neurona on lymphocyte proliferation to PMA/Ionomycin. Results were expressed as $\log$-transformed mean \pm SEM of triplicates. $n=8$ in infected horses and $\mathrm{n}=5$ uninfected controls. Asterisk indicated a significant difference within Day 0 samples $(P<0.05)$. Day is day prior to (D13) or following infection, e.g., D1. 


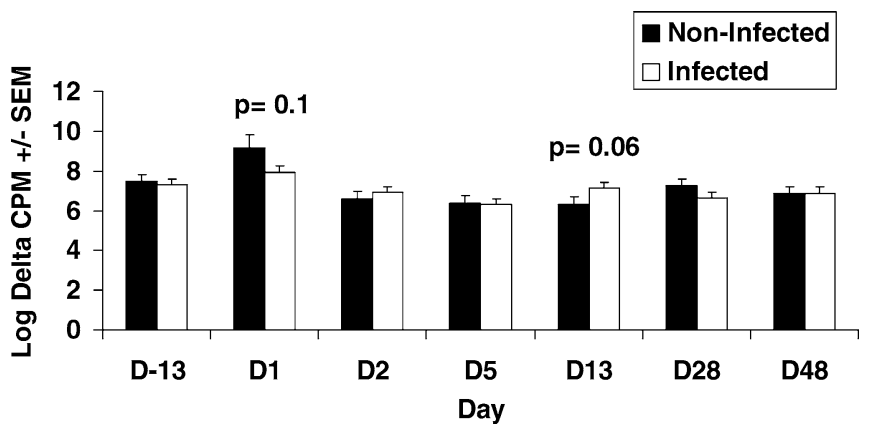

FIGURE 5. Proliferative response of lymphocytes from S. neuronainfected horses to $S$. neurona merozoites. Data for each group represented log-transformed mean \pm SEM of triplicates. There were 8 infected and 5 control horses. Day is day prior to (D-13) or following infection, e.g., D1.

versus control horses. However, there were trends $(P \leq 0.10)$ and some significant differences $(P<0.05)$ in CD8 cells and associated IFN-gamma production. When cells were stimulated with ConA for $18 \mathrm{hr}$ overnight, $S$. neurona-infected horses at Day 5 PI had a decreased percentage $(P<0.05)$ of CD8 cells present versus control horses (Fig. 6a). On Day 13 PI, when cells were stimulated overnight with ConA, there was a trend $(P=0.06)$ toward an increased percentage of CD8 cells in $S$. neurona-infected versus control horses. With regard to ConAstimulated CD8-mediated IFN-gamma production, there was a trend $(P=0.10)$ toward a significant interaction between date
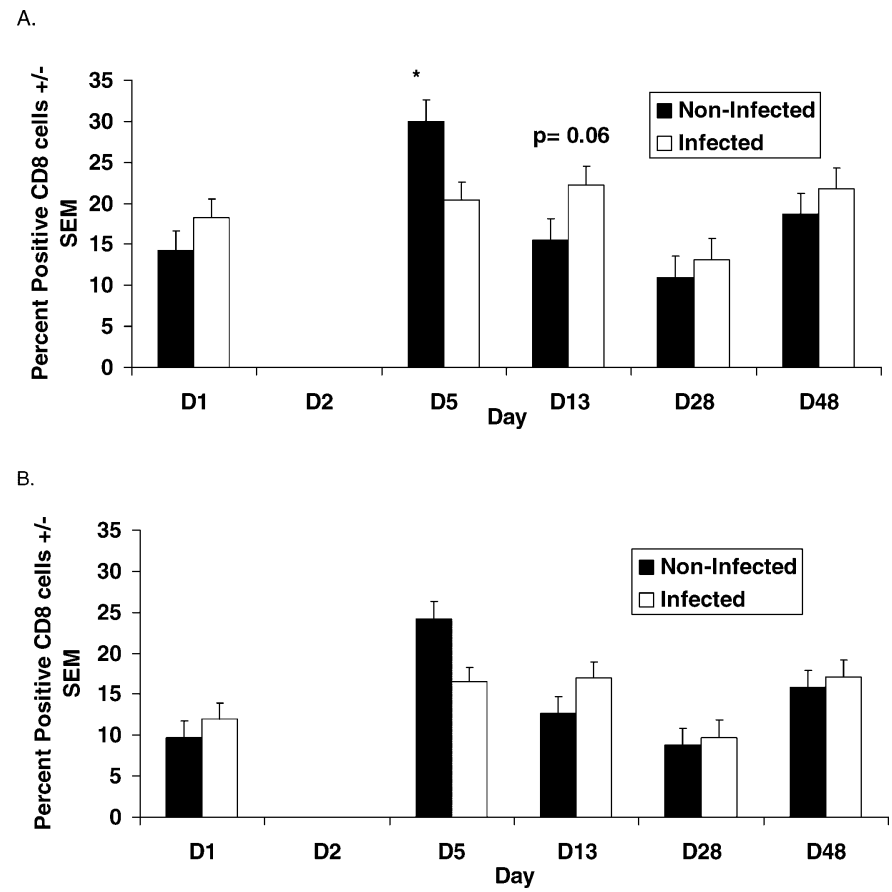

FIGURE 6. (a) Percentage of CD8 cells of total lymphocytes following overnight incubation with ConA. There were 8 infected and 5 control horses. Day is day prior to (D-13) or following infection, e.g., D1. Asterisk indicated a significant difference within Day 0 samples $(P<$ 0.05). (b) Percentage of CD8 cells of total lymphocytes that produce IFN-gamma (hi) when stimulated with ConA. There were 8 infected and 5 control horses. Day is day prior to (D-13) or following infection, e.g., D1.

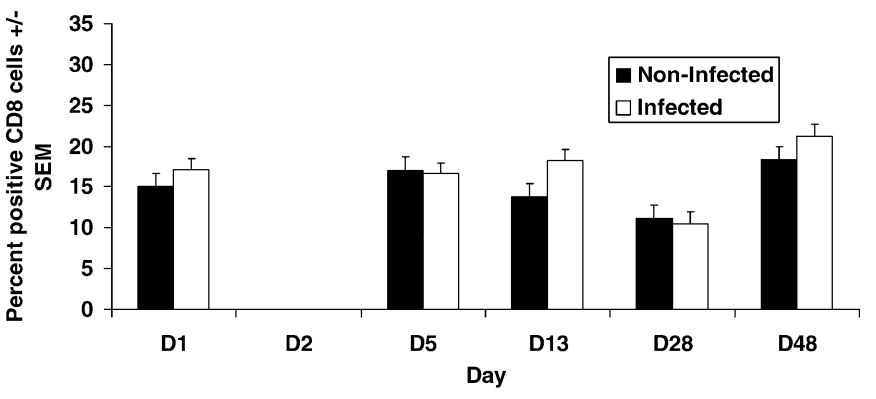

B.

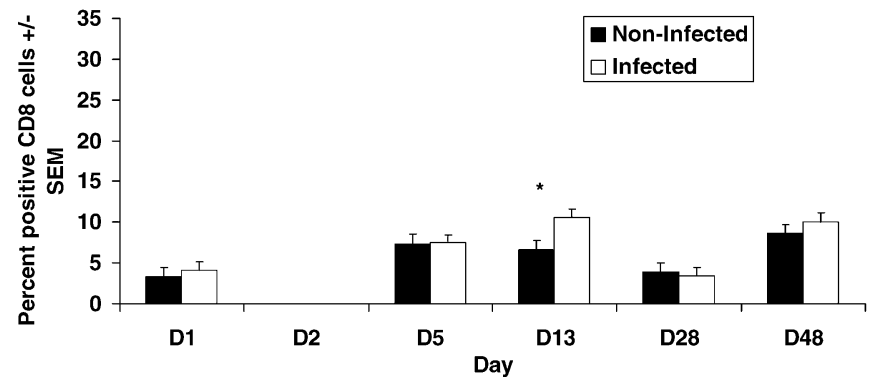

FIGURE 7. (a) Percentage of CD8 cells of total lymphocytes following overnight stimulation with merozoites. There were 8 infected and 5 control horses. Day is day prior to (D-13) or following infection, e.g., D1. (b) Percentage of CD8 cells of total lymphocytes producing IFNgamma (hi) when stimulated with merozoites. There were 8 infected and 5 control horses. Day is day prior to (D-13) or following infection, e.g., D1. Asterisk indicated a significant difference within Day 0 samples $(P<0.05)$.

and infection status. However, there were no significant differences in the percentage of ConA-stimulated CD8 cells producing IFN gamma between infected and control horses (Fig. 6b).

In regard to antigen-specific responses, there was a trend $(P$ $<0.08)$ in date by infection status for differences between $S$. neurona-infected versus control horses in the percentage of CD8 cells following overnight stimulation with $S$. neurona merozoites. At Day 13 PI, there was a trend toward increased CD8 cells in $S$. neurona-infected horses following $18 \mathrm{hr}$ overnight stimulation with merozoites compared to control horses (Fig. 7a). Correspondingly, there was a significant $(P<0.05)$ interaction between date and infection status for IFN-gamma production by CD8 cells stimulated with merozoites by infected versus control horses. At Day 13 PI, there was a trend $(P=$ 0.06) toward a higher percentage of CD8 producing IFN-gamma cells in $S$. neurona-infected horses compared to control horses (Fig. 7b). On Day 48 PI, there was also an increasing trend $(P=0.09)$ in IFN-gamma production by CD8 cells from infected horses following merozoite stimulation.

\section{DISCUSSION}

Results from this study show that horses experimentally infected with $S$. neurona do develop altered in vitro and in vivo immune responses. Furthermore, some of these altered immune responses are consistent with those present in horses naturally infected with EPM (Yang et al., 2006). The most significant 
finding was that horses experimentally infected with $S$. neurona do develop suppressed in vitro proliferation responses to PMA/I acutely following infection. Seven of 8 infected horses had suppressed in vitro immune responses to PMA/I 2 days following infection. Peripheral leukocytes that can respond to PMA/I include CD4, CD8, and B lymphocytes as well as NK cells. We will focus on determining the mechanism associated with the in vitro-suppressed PMA/I proliferation response. If we can determine whether and how $S$. neurona specifically mediates the changes in PMA/I proliferation, we may be able to use the assay as a supplemental diagnostic assay. Furthermore, if $S$. neurona mediates the suppression, we can determine whether there are other correlations between infection and the other changes in immune responses mentioned below.

With regard to changes in immune cell subsets and viability, we determined that at Day 28 PI, there was a significant decrease in the percentage of viable CD8 cells and a significant increase in the percentage of neutrophils in infected horses compared to controls. Also at Day 28 PI, there was a significant increase in the percentage of B cells in both infected and control horses. Additionally, at Day 48 PI, there was a decrease in the percentage of viable B cells in infected versus control horses.

The mechanisms associated with these changes have not been determined. Possible explanations for these changes at Day 28 PI include $S$. neurona-related changes (i.e., enhanced CD8 activity causing CD8 death due to infection) or statistically significant, but biologically irrelevant, changes. These findings will be further investigated in future studies to determine their significance.

The results from this study differ from our results in naturally infected horses in which we saw a slight but significant increase in the total percentage of CD4 cells (Yang et al., 2006). It also differs from Tornquist et al. (2001) who reported a lower percentage of CD4 cells in the EPM horses that were employed for that study. In all of these studies, the number of EPM horses was small. Possible explanations for the discrepancies between the studies include host conditions, i.e., immune competence, severity of disease, and time since infection, or parasite-specific factors, i.e., virulence or dose of organism. To verify whether $S$. neurona-infected horses do cause consistent changes in CD4 populations, we plan to perform additional studies.

With regard to antigen-specific proliferation responses to merozoites and SAG-1 antigen, no significant differences were observed. We believe that this could be due to the nonoptimized conditions of the assays for our laboratory at the time we performed the study. For the SAG-1 assay, we utilized Spencer et al. (2004) conditions. However, following completion of the study, we determined that a higher concentration of SAG-1 and longer incubation period were optimal. Additionally, for the merozoite proliferation assay, we determined that our previously optimized concentration of merozoites was suboptimal.

Another factor which likely affected the results was the strain of $S$. neurona employed for the antigen-specific proliferation and cytokine responses. We used S. neurona strain 37R (Sn37R) as a mitogen for this study, which we believed expressed 1 of the major immunodominant antigens, SAG-1. However, Howe et al. (2007) have recently determined (data not shown) that SN-37R does not express SAG-1. Furthermore, the $S$. neurona strain used to infect the horses did express SAG-1. Therefore, we did not have optimal conditions to assess antigen-spe- cific response based on the $S$. neurona strain employed for infecting the horses. In subsequent studies, we will utilize the revised SAG-1 conditions as well as optimized concentrations of a SAG-1 expressing strain of merozoites.

Overall, our results are inconsistent with the studies performed by others (Tornquist et al., 2001; Spencer et al., 2004). As stated, this could be because our conditions were not optimal for some of the antigen-specific assays, which could limit our ability to detect altered responses. In the studies by Spencer et al. (2004) and Tornquist et al. (2001), both groups found that EPM horses had suppressed $S$. neurona-stimulated proliferation responses. Neither group reported a mechanism for the suppressed responses. Spencer et al. (2005) later showed that leukocytes from the EPM horses had increased IL-4 expression. However, their study did not determine an association between altered cytokine expression and suppressed proliferative responses. Further studies are warranted to determine whether there is a correlation between altered IL-4 and IFN-gamma expression/production and proliferation responses. Other possible explanations for the differences in findings between the studies could be due to host factors associated with duration and severity of infection. Tornquist et al. (2001) appeared to have employed a range of horses with various durations of infection and severities of disease. Spencer et al. (2004) used a combination of both experimentally and naturally infected horses also of various durations of disease. For our study, we employed horses that were moderately acute (up to 48 days) PI. It is possible that the immune suppression may occur over some prolonged period of time, possibly associated with persistent infection. As we employed an experimental model in which the horses are normal prior to the study, there is a possible bias associated with the model that could influence our ability to detect $S$. neurona-specific immunomodulation. With our model, $S$. neurona is introduced into the host within the leukocytes, in a "Trojan horse" fashion, which potentially limits detection by the host immune response, at least early in infection. Therefore, it is possible, at least early postinfection, that there is a limited detection by the immune response to infection. Thus, our ability to detect these more minimal changes early postinfection is reduced. If this is true, then it may take a longer period of time to detect more significant changes in immune response. Therefore, following the horses for a longer period of time may provide additional meaningful data. Thus, although there are biases in utilizing this model, it is still an appropriate model to use. It may be that the time frame and/or degree nature of altered immune responses is somewhat delayed.

In addition to altered antigen-specific responses, $S$. neuronainfected horses also had suppressed in vitro immune responses to PMA/I. Interestingly, these data are consistent with those from horses naturally infected with EPM (Yang et al., 2006). We have also observed this same finding in another trial of experimentally infected horses (data not shown). Possible explanations for the response include decreased proliferation by a particular population(s), increased cell death/apoptosis of a particular population(s), altered signaling within the populations present, and/or $S$. neurona infection of the cells.

As our next step will be to determine the mechanisms of suppression, we will briefly discuss the most likely explanations. PMA binds cell-surface receptors containing tyrosine kinases. This triggers the signaling cascade, which includes mi- 
togen-induced protein kinase C (MAPK) and second messenger cAMP (Lodish et al., 2003; Yang et al., 2006). Once MAPK are activated, they translocate to the nucleus and bind members of the activated protein (AP-1) and nuclear factor kappa B (NF$\mathrm{kB})$ family in the nucleus, including NF-kB1, as well as nuclear factor of activated $\mathrm{T}$ cells (NFAT). These factors then alter gene transcription (Thanos and Maniatis, 1995). By contrast, ionomycin alters calcium stores, increasing calcium influx within the cell (Liu and Hermann, 1978; Yang et al., 2006). Additionally, it has been demonstrated that ionomycin and other ionophores can cause $S$. neurona (Ellison et al., 2001) and T. gondii (Arrizabalaga and Boothroyd, 2004) to egress from host cells. Furthermore, Masek et al. (2007) demonstrated that extracellular sources of calcium were needed for $T$. gondii to induce intracellular changes in calcium within macrophage cell lines. The subsequent effects of infection and alteration of intracellular calcium levels were not determined.

Based on this information, it is clear that $S$. neurona infection correlates with PMA/I induced in vitro suppression in both naturally and experimentally infected horses. As we have found that these suppressed in vitro responses are present in both naturally and experimentally infected horses, we believe that this finding is very meaningful. If the mechanisms can be determined, it may provide critical information as to how $S$. neurona infects cells. This could shed some light on a possible means by which immune suppression or modulation could occur. Further, this assay could be used as a supplemental diagnostic assay for the early detection of horses with $S$. neurona infection and/ or EPM. Although this is an in vitro test, if there is a high correlation with $S$. neurona infection and suppressed response, this could be use to detect EPM cases early in disease. In doing so, treatment could be initiated quickly and outcomes could be improved.

In addition to assessment of immune function based on proliferative responses, T-cell function was also assessed based on IFN-gamma production. We found that at Day 5 PI, CD8 cells from infected versus control horses had decreased cell proliferation when stimulated with ConA, and there was a trend toward decreased interferon gamma production by CD8 cells stimulated with ConA. Spencer et al. (2005) has reported an increase in IL-4 gene transcription from cells of EPM horses. IL-4 is produced primarily by CD4 Th2 and CD8 Tc2 cells, whereas Tc1 and Th1 cells produce interferon gamma. Typically, 1 cell type will dominate the response, i.e., either Th1 and Tc1 cells or Th2 and Tc2 cells. Therefore, if there is a decrease in IFN gamma, there will often be a corresponding increase in IL-4 by the associated T-cell populations. Based on this information, additional studies are warranted to determine whether protein levels of IL-4 are increased and with a corresponding decreased IFN-gamma production.

From the study described here, we have demonstrated that horses experimentally infected with $S$. neurona develop altered immune function responses. The most significant is that by Day 2 PI, 7 of the 8 infected horses had lymphocytes with suppressed in vitro proliferation responses to PMA/I. These data are also consistent with our data in naturally infected horses with EPM (Yang et al., 2006). These findings support the use of our experimental model (Ellison et al., 2004) of infection in order to investigate further the mechanisms of PMA/I-stimulated in vitro suppression, as this may reveal more information regarding the host-pathogen interactions of $S$. neurona in horses. Additionally, if the mechanism of suppression can be determined, this assay may have potential as a supplemental diagnostic test in the diagnosis of EPM.

\section{ACKNOWLEDGMENTS}

We wish to thank Joan Kalnitsky for technical help in flow cytometry. This project was funded by a Patricia Bonsall Stuart Award for Equine Studies and Paramutual Racing Funds from Virginia Tech.

\section{LITERATURE CITED}

Arrizabalaga, G., And J. Boothroyd. 2004. Role of calcium during Toxoplasma gondii invasion and egress. International Journal for Parasitology 34: 361-368.

Belz, G., W. XIE, AND P. Doherty. 2001. Diversity of epitope and cytokine profiles for primary and secondary influenza A virus specific CD8 + T cells responses. Journal of Immunology 166: 46274633.

Dubey, J. P., S. W. Davis, C. A. Speer, D. D. Bowman, A. De Lahunta, D. E. Granstrom, M. J. Topper, A. N. Hamir, J. F. Cummings, AND M. M. SuTER. 1991. Sarcocystis neurona n. sp. (Protozoa: Apicomplexa), the etiologic agent of equine protozoal myeloencephalitis. Journal of Parasitology 77: 212-218.

, AND D. S. LINDSAY. 1998. Isolation in immunodeficient mice of Sarcocystis neurona from opossum (Didelphis virginiana) faeces, and its differentiation from Sarcocystis falcatula. International Journal for Parasitology 28: 1823-1828.

Ellison, S., E. Greiner, AND J. DAME. 2001. In vitro culture and synchronous release of Sarcocystis neurona merozoites from host cells. Veterinary Parasitology 95: 251-261.

, K. Brown, AND T. Kennedy. 2004. Experimental infection of horses with culture-derived Sarcocystis neurona merozoites as a model for equine protozoal myeloencephalitis. International Journal of Applied Research in Veterinary Medicine 2: 7989

, T. KENNEDy, AND K. BRown. 2003a. Development of an ELISA to detect antibodies to r-SAG-1 in the horse. Journal of Applied Research in Veterinary Medicine 1: 318-327.

— AND . 2003b. Early signs of equine protozoal myeloencephalitis. Journal of Applied Research in Veterinary Medicine 1: 272-278.

, A. Omara-Opyene, C. Yowell, A. Marsh, and J. Dame. 2002. Molecular characterization of a major $29 \mathrm{kDa}$ surface antigen of Sarcocystis neurona. International Journal for Parasitology 32: 217-225.

Gazzinelli, R., I. Eltoum, T. Wynn, And A. Sher. 1993. Acute cerebral toxoplasmosis is induced by in vivo neutralization of TNF-alpha and correlates with the down-regulated expression of inducible nitric oxide synthase and other markers of macrophage activation. Journal of Immunology 151: 3672-3681.

- , Y. Xu, S. Hieny, A. Cheever, And A. Sher. 1992. Simultaneous depletion of CD4+ and CD8 $+\mathrm{T}$ lymphocytes is required to reactivate chronic infection with Toxoplasma gondii. Journal of Immunology 149: 175-180.

Gogal, R. M., JR., B. Smith, And J. Kalnitsky. 2000. Analysis of apoptosis of lymphoid cells in fish exposed to immunotoxic compounds. Cytometry 39: 310-318.

Granstrom, D. E., J. P. Dubey, S. W. Davis, R. Fayer, J. C. Fox, K. B. Poonacha, R. C. Giles, and P. F. Comer. 1993. Equine protozoal myeloencephalitis: Antigen analysis of cultured Sarcocystis neurona merozoites. Journal of Veterinary Diagnostic Investigation 5: 88-90.

Hines, S., D. Stone, M. Hines, D. C. Alperin, D. P. Knowles, L. K. Norton, M. J. Hamilton, W. C. Davis, and T. C. McGuire. 2003. Clearance of virulent but not avirulent Rhodococcus equi from the lungs of adult horses is associated with intracytoplasmic $\gamma$-interferon production by CD4 and CD8 T lymphocytes. Clinical and Diagnostic Laboratory Immunology 10: 208-215.

Howe, D. K., R. Y. Gaji, A. E. Marsh, B. A. Patil, W. J. Saville, D. S. Lindsay, J. P. Dubey, and D. E. Granstrom. 2007. Strains of 
Sarcocystis neurona exhibit differences in their surface antigens, including the absences of the major surface antigen SnSAG1. International Journal for Parasitology. (In press.)

Lindsay, D. S., N. J. Thomas, AND J. P. Dubey. 2000. Biological characterisation of Sarcocystis neurona isolated from a Southern sea otter (Enhydra lutris nereis). International Journal for Parasitology 30: 617-624.

LiU, C. M., AND T. E. HeRMANN. 1978. Characterization of ionomycin as a calcium ionophore. Journal of Biological Chemistry 253: $5892-5894$

Lodish, H., A. Berk, S. L. Zipursky, P. Matsudaira, D. Baltimore, AND J. E. DARnell. 2003. Molecular cell biology, 5th ed. W. H. Freeman \& Co., New York, New York, 970 p.

MACKAY, R. J. 1997a. Serum antibodies to Sarcocystis neurona-Half the horses in the United States have them! Journal of the American Veterinary Medical Association 210: 482-483.

- 1997b. Equine protozoal myeloencephalitis. Veterinary Clinics of North America: Equine Practice 13: 79-96.

Masek, K. S., P. Zhu, B. D. Freeman, and C. A. Hunter. 2007. Toxoplasma gondii induces changes in intracellular calcium in macrophages. Parasitology 134: 1973-1979.

National Animal Health Monitoring System (NAHMS). 2001. Equine protozoal myeloencephalitis in the United States. USDA: AOHIS: VS, CEAH, Fort Collins, CO, No. N312.0501.

REED, S. 1998. Neurologic examination. In Equine internal medicine, S. Reed and W. Bayly (eds.). W. B. Saunders, Philadelphia, Pennsylvania, p. 427-434.

Saville, W. J., S. M. Reed, And P. Morely. 2000. Analysis of risk factors for the development of equine protozoal myeloencephalitis in horses. Journal of the American Veterinary Medical Association 217: $1174-1180$

Sellon, D. C., D. P. Knowles, E. C. Greiner, M. T. Long, M. T. Hines, T. Hochstatter, K. M. Hasel, M. Ueti, K. Gillis, and J. B. Dame. 2004. Depletion of natural killer cells does not result in neurologic disease due to Sarcocystis neurona in mice with severe combined immunodeficiency. Journal of Parasitology 90: 782-788.

Shapira, S., O. Harb, J. CaAman, And C. Hunter. 2004. The NF-kB signaling pathway: Immune evasion and immunoregulation during toxoplasmosis. International Journal for Parasitology 34: 393-400.

Spencer, J. A., P. Deinnocentes, E. M. Moyana, A. J. Guarino, S. E.
Ellison, R. C. Bird, And B. L. Blagburn. 2005. Cytokine gene expression in response to SnSAG1 in horses with equine protozoal myeloencephalitis. Clinical and Diagnostic Laboratory Immunology 12: 644-646.

, S. E. Ellison, A. J. Guarino, and B. L. Blagburn. 2004. Cell-mediated immune responses in horses with equine protozoal myeloencephalitis. Journal of Parasitology 90: 428-430.

Splitter, G., S. Oliveira, S., M. Carey, C. Miller, J. Ko, and J. COVERT. 1996. T lymphocyte mediated protection against facultative intracellular bacteria. Veterinary Immunology and Immunopathology 54: 309-319.

SuZUKI, Y. 2002a. Host resistance in the brain against Toxoplasma gondii. Journal of Infectious Disease 185(Suppl. 1): S58-S65.

2002b. Immunopathogenesis of cerebral toxoplasmosis. Journal of Infectious Disease 186(Suppl. 2): S234-S240.

Thanos, D., And T. Maniatis. 1995. NF-kappa B: A lesson in family values. Cell 80: 529-532.

Tornouist, S. J., L. J. Boeder, D. E. Mattson, C. K. Cebra, R. J. BildFell, AND A. N. HAMIR. 2001. Lymphocyte responses and immunophenotypes in horses with Sarcocystis neurona infection. Equine Veterinary Journal 33: 726-729.

Witonsky, S. G., R. M. Gogal, R. B. Duncan, and D. S. Lindsay. 2003a. Protective immune response to Sarcocystis neurona infection in C57BL/6 mice. Journal of Parasitology 89: 924-931.

- AND - 2003b. Immunopathologic effects associated with Sarcocystis neurona infected interferon- $\gamma$ knock-out mice. Journal of Parasitology 89: 932-940.

$-\longrightarrow,-$ H. Norton, D. WARd, And D. S. Lindsay. 2005. Prevention of meningo/encephalomyelitis due to Sarcocystis neurona infection in mice is mediated by CD8 cells. International Journal for Parasitology 35: 113-123.

V. B. Maxwell, AND S. A. Ahmed. 2003. Immunologic analysis of blood samples obtained from horses and stored for twenty-four hours. American Journal of Veterinary Research 64: 1003-1009.

Yang, J., S. Ellison, R. M. Gogal, H. Norton, D. Ward, D. S. LindSAY, AND S. G. WITONSKY. 2006. Investigation of immune response to Sarcocystis neurona infection in naturally infected horses with equine protozoal myeloencephalitis. Veterinary Parasitology 138: $200-210$ 